\title{
Passive Smoking and the Development of Cardiovascular Disease in Children: A Systematic Review
}

\author{
Giorgos S. Metsios, ${ }^{1,2}$ Andreas D. Flouris, ${ }^{2}$ Manuela Angioi, ${ }^{1}$ and Yiannis Koutedakis ${ }^{1,3}$ \\ ${ }^{1}$ School of Sport, Performing Arts and Leisure, University of Wolverhampton, Walsall, West Midlands WS1 3BD, UK \\ ${ }^{2}$ Fame Laboratory, Institute of Human Performance and Rehabilitation, Center for Research and Technology, 42100 Thessaly, Greece \\ ${ }^{3}$ Research Institute in Physical Performance and Rehabilitation, Center for Research and Technology, Thessaly, Trikala, Greece
}

Correspondence should be addressed to Giorgos S. Metsios, g.metsios@wlv.ac.uk

Received 20 June 2010; Accepted 21 July 2010

Academic Editor: Demosthenes Panagiotakos

Copyright (C) 2011 Giorgos S. Metsios et al. This is an open access article distributed under the Creative Commons Attribution License, which permits unrestricted use, distribution, and reproduction in any medium, provided the original work is properly cited.

Passive smoking may be implicated in the development of cardiovascular disease (CVD) in children because of their partially developed physiological systems. The aim of the present systematic paper is to investigate whether passive smoking is associated with factors that influence the development of CVD in children. Data sources included Medline, Cochrane Library, Cumulative Index to Nursing \& Allied Health (CINAHL) research database, Google Scholar, Excerpta Medica database (EMBASE), the 2006 Office of the Surgeon General's report, and the 2005 report from the California Environmental Protection Agency. We identified a total of 42 relevant articles (i.e., 30 reviews and 12 observational). Results revealed that passive smoking may be implicated in deteriorating cardiovascular status in children in terms of unfavorable high-density lipoprotein levels and deteriorated vascular function.

\section{Introduction}

Active smoking and disease is a research area investigated for many decades. The first ever case-control studies which revealed a strong association between active smoking and lung cancer were conducted in Nazi Germany in 1939 and 1943 [1]. Many other studies, thereafter, have explored the effects of tobacco smoke on human health. It is now an accepted fact that smoking is responsible for the development of chronic diseases as well as increased morbidity and mortality [2].

During the last decades research has also expanded in the area of passive smoking (PS) and its effects on aspects of human health. The first conclusive evidence on the danger of PS arose in 1981 from a study showing that nonsmoking Japanese women married to men who smoked had an increased risk for lung cancer [3]. Since then, a vast number of studies have appeared investigating the unfavorable effects of PS. In line with active smoking, it is now generally accepted that PS leads to increased prevalence of various cardiovascular diseases [4] and increases the risk of death by at least $20 \%$ [5]. More importantly, recent methodologically robust data from nonsmoking adults have shown that PS compromises health not only when individuals are exposed frequently for prolonged periods of time-as initially thought - but also after a single brief exposure [610]. This novel evidence clearly shows that PS may have a substantive role in the development of chronic diseases [11].

Despite the recent measures adopted in different countries to eliminate indoor smoking, 700 million children globally are still exposed to environmental tobacco smoke [12] while the smoking epidemic continues to increase worldwide [13]. Given that tobacco smoke contains chemicals characterized as carcinogenic (e.g., benzene, chlorinated dioxins, and benzo $[a]$ pyrene) and have adverse health consequences on the cardiovascular (e.g., arsenic) and respiratory (e.g., acetaldehyde) systems in adults [14], the physiologically immature children may be more vulnerable to damage as a result of PS exposure because of their partially developed or compromised cardiovascular, endocrine, and immune systems. For these reasons, we conducted a systematic review 
of the available literature to investigate the evidence regarding PS and its association with factors that influence the development of cardiovascular disease (CVD) in children.

\section{Methods}

Five databases [Medline, Cochrane Library, Cumulative Index to Nursing \& Allied Health (CINAHL) research database, Google Scholar, Excerpta Medica database (EMBASE)], the 2006 report on second hand smoke by the Office of the Surgeon General [4], and the 2005 report by the California Environmental Protection Agency [15] were searched to identify publications from 1975 to April 2009 in English regarding PS and cardiovascular disease in children ( $<18$ years old). The Medical Subject Heading $(\mathrm{MeSH})$ terms "PS," "second hand smoking," "environmental tobacco smoking", "maternal smoking," and "parental smoking", were searched in combination with "obesity", "diabetes," "hypertension," "blood pressure," "cholesterol," "lipids," and "cardiovascular disease." Editorials and conference proceedings were excluded. If the abstract did not provide sufficient information for this process, then the full-text manuscript was examined. The cited articles of the selected papers were also searched manually in order to identify relevant studies not identified in the original search. A flow diagram of the studies identified from databases and the combination of key words used to identify the observational studies included in the present paper in Figure 1.

\section{Results}

We identified a total of 77 articles, from which only 42 were relevant; of which 30 were reviews and 12 were observational studies and thus included in the present paper. Table 1 depicts the results of each study included in the present paper $(n=12)$.

From the results of the present paper it appears that newborn children exposed to PS at home are more likely to be overweight and obese, particularly when exposed during the first three years of their life [16]. It was also found that PS is associated with deteriorated blood lipids profiles in children, particularly lower high-density lipoprotein which has been a consistent finding in most studies [17-21]. A randomized controlled trial (RCT) also revealed that in passive smokers the rate of factors associated with the development of CVD, such as body weight, cholesterol, and triglycerides, was higher than that in non-PS smokers [22].

PS in children has also been examined in relation to vascular biological parameters. PS appears to directly affect endothelial function in children via a dose-dependent decrease in the bioavailability of nitric oxide [23]. Two randomized controlled studies (RCTs) found that children exposed to PS have also reduced aortic elasticity possibly via the direct effects of PS on the mechanical properties of the arteries (e.g., impaired nitric oxide production, platelet activation, or adrenalin levels) $[23,24]$.
The effects of exposure to PS during pregnancy with regards to risks factors associated with CVD were investigated in two separate studies. Results revealed a significantly higher concentration of cotinine in children due to exposure to PS from the mother during pregnancy [25] and that PS increased oxidative stress in cord blood [26]. The effects of maternal PS exposure on absolute red blood counts (RBC) were assessed in newborn infants of 55 mothers exposed and 31 not exposed to PS during the last trimester; data revealed that the counts of absolute nucleated RBCs were significantly elevated in the PS exposed group. Table 1 depicts the results of all studies identified in relation to PS and CVD in children.

\section{Discussion}

The present systematic review investigated the effects of PS on CVD (classical risk factors and vascular function) in children. The results reveal that PS may be implicated in deteriorating cardiovascular status in terms of unfavorable high-density lipoprotein levels and deteriorated vascular function, whereas the mechanisms by which PS negatively affect the cardiovascular status of children (in terms of classical CVD risk factors) have yet to be elucidated. Perhaps, the significant decrease in cardiorespiratory function, as a result of smoking/PS, leads to a decrease in physical activity in children which may then have a significant unfavorable impact on body fat and cholesterol levels. This is supported by a vast amount of evidence demonstrating that physical inactivity results in worse profile in classical CVD risk factors in both healthy and diseased populations [28-30].

Two RCT studies [23, 24] have consistently revealed that children exposed to PS have reduced aortic elasticity. The significant alterations in vascular biological mechanisms from an early age may lead to a deteriorated health status of children exposed to PS, given that vascular dysfunction precedes atherosclerosis and leads to increased CVD mortality [31, 32]. PS appears to directly affect endothelial function in children via a dose-dependent decrease in nitric oxide [23], a mechanism preceding atherosclerosis [31]. Vascular endothelial dysfunction has been implicated in the progression of atherosclerosis and cardiovascular event rates; hence, its assessment may provide pivotal information, particularly given that it may detect "silent" clinical manifestations leading to ischaemia. This is the reason why this assessment is consistently used in research and clinical setting for both prognostic and diagnostic means. Nitric oxide is a vasoactive factor responsible for dilation of the vessels; the drop in exhaled nitric oxide levels within the first minutes of PS may be caused by decreased production of nitric oxide synthase through a negative feedback mechanism, given the high concentrations of nitrogen oxides inherent in tobacco smoke [33]. Possible other mechanisms comprise an increased breakdown of nitric oxide by PS oxidants or a PSinduced accelerated uptake of nitric oxide [34].

Data from adults have shown that the PS-induced changes in lipoprotein oxidization generate various effects in the vessel wall [35]. Animal experiments have shown a synergistic effect between PS and lipoprotein that influence 


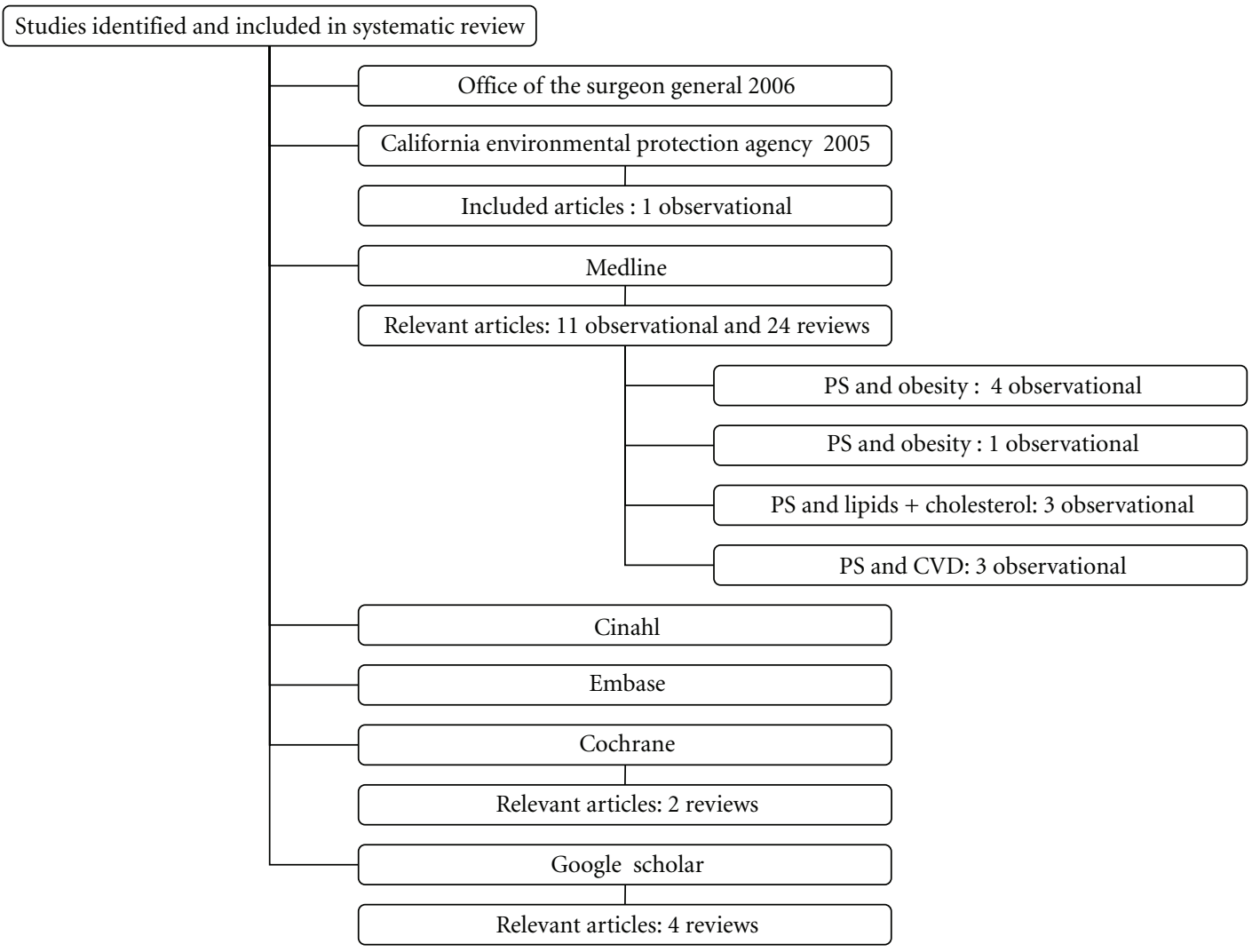

FIGURE 1: Articles identified and included in systematic review.

the oxidation of lipoprotein in the vessel wall [36]. It is also important to note that polycyclic aromatic hydrocarbonsbyproducts of the incomplete combustion of organic material inherent in PS - bind to lipoprotein subfractions and can be integrated into the atheromatic plaques promoting the proliferation of vascular cells and plaque progression [35].

Elevated absolute nucleated RBCs count in the neonate, as observed by Cochran-Black et al. [27], is a marker of fetal hypoxia [15]. Periods of hypoxia may stimulate bone marrow to increase the hematocrit possibly in concert with a more rapid smoke-induced RBC turnover. The findings from this study suggest that maternal PS exposure has similar effects on the fetus as active maternal smoking.

It is of great clinical importance to explore the associations between PS and either pregnancy or early childhood. Clearly, PS has well-established adverse health effects in children $[37,38]$ whereas the mechanisms by which PS affects the fetus may be different to those that affect the child or adolescent; the deterioration in cardiorespiratory and immune system as well as the toxic substances in tobacco smoke are currently the main suggested mechanisms. Through this systematic review of the current available data, it appears that paternal PS promotes the development of CVD. However, we have previously demonstrated-by using a robust methodological design - that in young adults, even the normal PS exposures (similar to those seen in public places and houses) may significantly compromise health parameters [6-8]. Minimizing children's exposure to PS should therefore be amongst the main aims of interventional studies in order to raise public awareness and improve parent education and counseling.

There are several limitations in the methodological designs of studies conducting research on the effects of PS on children's health. Most of the studies do not take into account very important confounding factors such as the environmental ones (e.g., exposure to other carcinogenic substances) or maternal diet and obesity that may indeed result in increasing CVD prevalence in children. Most importantly, the adopted designs allow only for crosssectional comparisons, in which the directionality and causality of associations cannot be clearly justified. Also, the vast majority of published studies justify PS on self-reports without an objective measurement of exposure (e.g., cotinine levels). Moreover, it may be possible that PS has indirect effects on CVD outcomes in children, via its immunosuppressive capabilities [37]. For example, it is estimated that PS is equivalent to smoking $\sim 100$ cigarettes per year. This number, however, ranges according to the smoking habits of parents [39]. It has been found that even 30 minutes of PS significantly deteriorate cardiovascular outcomes similarly to smoking [40]. Hence, it seems reasonable to suggest that the physiologically undeveloped systems of fetus/children may be more susceptible to damage from the toxic effects of PS, particularly given the fact that the effects of PS may occur at very low levels of exposure [41]. 
TABle 1: The effects of PS on CVD.

\begin{tabular}{|c|c|c|c|}
\hline Author [reference] & Design & Participants & Results \\
\hline Apfelbacher et al. [16] & Cohort cross-sectional & $\begin{array}{l}35,434 \text { children ( } 50.9 \% \text { boys), } \\
5-7 \text { years old }\end{array}$ & $\begin{array}{l}\text { PS was a predictor of being overweight and/or } \\
\text { obese }\end{array}$ \\
\hline Öhrig et al. [22] & RCT & 3495 children (age $6.5 \pm 2$ years) & $\begin{array}{l}\text { In passive smokers the rates of body weight, } \\
\text { cholesterol, and triglycerides were higher }\end{array}$ \\
\hline Hargrave et al. [25] & Controlled Clinical trial & $\begin{array}{l}\text { Children-specific numbers not } \\
\text { mentioned }\end{array}$ & $\begin{array}{l}\text { Significantly higher concentration of cotinine } \\
\text { found in children due to exposure in PS from } \\
\text { the mother rather than that from father/friends }\end{array}$ \\
\hline Aycicek and Ipek [26] & Clinical trial & Mothers giving birth & PS increased oxidative stress in cord blood \\
\hline Kallio et al. [23] & RCT & 441 children (8-11 years) & PS impairs endothelial function in children \\
\hline Kallio et al. [24] & RCT & 386 children ( 11 years) & PS impairs aortic elasticity \\
\hline Neufeld et al. [19] & Cross-sectional (pilot scale) & $\begin{array}{l}161 \text { children and adolescence } \\
(2-18 \text { years })\end{array}$ & $\begin{array}{l}\text { High density lipoprotein was significantly } \\
\text { lower in passive smokers. PS may increase the } \\
\text { risk profile for later atherosclerosis }\end{array}$ \\
\hline Moskowitz et al. [17] & Longitudinal & $\begin{array}{l}105 \text { PS twin pairs and } 111 \\
\text { non-PS twin pairs (all } \\
\text { preadolescent children) }\end{array}$ & $\begin{array}{l}\text { HDL was lower in PS children. Also, significant } \\
\text { adverse alterations were already present in } \\
\text { lipoprotein profiles in twin exposed to PS }\end{array}$ \\
\hline Moskowitz et al. [18] & Cohort analytic & 408 twins ( 11 years at baseline) & $\begin{array}{l}\text { HDL is significantly lower in passive smokers. } \\
\text { White males that have a history of higher CVD, } \\
\text { or higher weight, and/or blood pressure may } \\
\text { be at increased risk for developing premature } \\
\text { CVD }\end{array}$ \\
\hline Feldman et al. [20] & Cross-sectional & Healthy adolescents & $\begin{array}{l}\text { Lower high density lipoprotein in passive } \\
\text { smokers }\end{array}$ \\
\hline Işcan et al. [21] & Cross-sectional & 194 healthy children ( $4-14$ years) & $\begin{array}{l}\text { Total cholesterol, low-density lipoprotein were } \\
\text { significantly higher in passive smokers }\end{array}$ \\
\hline Cochran-Black et al. [27] & Cross-sectional & $\begin{array}{l}55 \text { mothers exposed to PS and } 31 \\
\text { not exposed to PS }\end{array}$ & $\begin{array}{l}\text { No significant differences in counts for total } \\
\text { red blood cells, white blood cells, platelets, and } \\
\text { lymphocytes. Absolute nucleated RBCs } \\
\text { significantly elevated in the PS exposed group. }\end{array}$ \\
\hline
\end{tabular}

The fact that the majority of the available published paper on this research area were reviews rather than original research investigations demonstrates the difficulty of performing research on PS and CVD in children. We have performed a systematic review of the literature in order to be objective rather than assume causality and report only results that favor directionality of associations, which appears to be the case in many published papers. Based on the available findings, interventions that target the cessation of parental smoking at home and preconception parental smoking, are necessary. Despite that indoor PS has been banned in many countries, PS at home is the most difficult to control and at the moment pulled data from systematic study reveal that interventions to reduce exposure in children are ineffective [42].

The findings of this systematic paper are particularly timely given the emerging experimental evidence on the adverse effects of passive smoking on health [6-8], as well as the shifting global smoking patterns, with an estimated 930 million of the world's 1.1 billion smokers living in developing countries, that also demonstrate increasing smoking rates amongst young individuals $[30,43]$. The findings of this paper indicate that public health preventive actions toward minimizing the exposure of children to PS should aim not only at suppressing tobacco use, but should also target family influence as attitudes that reinforce smoking behaviors and increase the exposure of children to PS.

\section{Conclusions}

We conclude that the current available data reveal that PS in children is linked with deteriorated lipid profile and vascular function whereas data for maternal smoking (during pregnancy and PS after birth) are still inconclusive mainly due to design constrains and lack of adjusting because of important confounding factors.

\section{Conflict of Interests}

The Authors have no Conflict of Interests.
Abbreviations
PS: $\quad$ Passive smoking
CVD: Cardiovascular disease
CINAHL: Cumulative Index to Nursing \& Allied Health
EMBASE: Excerpta Medica database
MeSH: Medical subject heading. 


\section{References}

[1] R. N. Proctor, Racial Hygiene. Medicine under the Nazis, Harvard University Press, Cambridge, Mass, USA, 1988.

[2] L. Gruer, C. L. Hart, D. S. Gordon, and G. C. M. Watt, "Effect of tobacco smoking on survival of men and women by social position: a 28 year cohort study," BMJ, vol. 338, no. 7695, 2009.

[3] T. Hirayama, "Non-smoking wives of heavy smokers have a higher risk of lung cancer: a study from Japan," Bulletin of the World Health Organization, vol. 78, no. 7, pp. 940-942, 2000.

[4] US Department of Health and Human Services, US Department of Health and Human Services CfDCaP, and National Center for Chronic Disease Prevention and Health Promotion, Office on Smoking and Health, "The health consequences of involuntary exposure to tobacco smoke: a report of the Surgeon General," Atlanta, Ga, USA, 2006.

[5] S. A. Glantz and W. W. Parmley, "Passive and active smoking: a problem for adults," Circulation, vol. 94, no. 4, pp. 596-598, 1996.

[6] A. D. Flouris, G. S. Metsios, A. E. Carrillo et al., "Acute and short-term effects of secondhand smoke on lung function and cytokine production," American Journal of Respiratory and Critical Care Medicine, vol. 179, no. 11, pp. 1029-1033, 2009.

[7] A. D. Flouris, G. S. Metsios, A. Z. Jamurtas, and Y. Koutedakis, "Sexual dimorphism in the acute effects of secondhand smoke on thyroid hormone secretion, inflammatory markers and vascular function," American Journal of Physiology, vol. 294, no. 2, pp. E456-E462, 2008.

[8] G. S. Metsios, A. D. Flouris, A. Z. Jamurtas et al., "Brief report: a brief exposure to moderate passive smoke increases metabolism and thyroid hormone secretion," Journal of Clinical Endocrinology and Metabolism, vol. 92, no. 1, pp. 208-211, 2007.

[9] N. Sidorkewicz, A. E. Carrillo, G. S. Metsios, A. D. Flouris, A. Z. Jamurtas, and Y. Koutedakis, "Resting energy expenditure response following environmental tobacco smoke exposure," Medicine \& Science in Sports \& Exercise, vol. 38, no. 5, pp. 457458, 2006.

[10] A. D. Flouris, G. S. Metsios, A. E. Carrillo, et al., "Effects of passive smoking on resting and exercising humans," Canadian Journal of Applied Physiology, vol. 30, p. 28, 2005.

[11] M. D. Eisner, "Secondhand smoke and obstructive lung disease: a causal effect?" American Journal of Respiratory and Critical Care Medicine, vol. 179, no. 11, pp. 973-974, 2009.

[12] L. Rushton, "Health impact of environmental tobacco smoke in the home," Reviews on Environmental Health, vol. 19, no. 3-4, pp. 291-309, 2004.

[13] J. Mackay and M. Eriksen, The Tobacco Atlas, World Health Organization, Geneva, Switzerland, 2008.

[14] International Agency for Research on Cancer (IARC), Monographs on the Evaluation of Carcinogenic Risk of Chemicals to Humans, vol. 83 of Tobacco Smoke and Involuntary Smoking, IARC, Lyon, France, 2004.

[15] M. D. Miller, R. Broadwin, S. Green, et al., Health Effects Assessment for Enviromental Tobacco Smoke, California Environmental Protection Agency, Sacramento, Calif, USA, 2005.

[16] C. J. Apfelbacher, A. Loerbroks, J. Cairns, H. Behrendt, J. Ring, and U. Krämer, "Predictors of overweight and obesity in five to seven-year-old children in Germany: results from crosssectional studies," BMC Public Health, vol. 8, article no. 171, 2008.

[17] W. B. Moskowitz, M. Mosteller, R. M. Schieken et al., "Lipoprotein and oxygen transport alterations in passive smoking preadolescent children. The MCV Twin Study," Circulation, vol. 81, no. 2, pp. 586-592, 1990.

[18] W. B. Moskowitz, P. F. Schwartz, and R. M. Schieken, "Childhood passive smoking, race, and coronary artery disease risk: the MCV twin study," Archives of Pediatrics and Adolescent Medicine, vol. 153, no. 5, pp. 446-453, 1999.

[19] E. J. Neufeld, M. Mietus-Snyder, A. S. Beiser, A. L. Baker, and J. W. Newburger, "Passive cigarette smoking and reduced HDL cholesterol levels in children with high-risk lipid profiles," Circulation, vol. 96, no. 5, pp. 1403-1407, 1997.

[20] J. Feldman, I. R. Shenker, R. A. Etzel et al., "Passive smoking alters lipid profiles in adolescents," Pediatrics, vol. 88, no. 2, pp. 259-264, 1991.

[21] A. Işcan, B. S. Uyanik, N. Vurgun, A. Ece, and M. R. Yiğitoğlu, "Effects of passive exposure to tobacco, socioeconomic status and a family history of essential hypertension on lipid profiles in children," Japanese Heart Journal, vol. 37, no. 6, pp. 917923, 1996.

[22] E. Öhrig, H. C. Geiß, G.-M. Haas, and P. Schwandt, "The Prevention Education Program (PEP) nuremberg: design and baseline data of a family oriented intervention study," International Journal of Obesity, vol. 25, supplement 1, pp. S89-S92, 2001.

[23] K. Kallio, E. Jokinen, O. T. Raitakari et al., "Tobacco smoke exposure is associated with attenuated endothelial function in 11-year-old healthy children," Circulation, vol. 115, no. 25, pp. 3205-3212, 2007.

[24] K. Kallio, E. Jokinen, M. Hämäläinen et al., "Decreased aortic elasticity in healthy 11-year-old children exposed to tobacco smoke," Pediatrics, vol. 123, no. 2, pp. e267-e273, 2009.

[25] D. R. Hargrave, C. McMaster, M. M. T. O'Hare, and D. J. Carson, "Tobacco smoke exposure in children and adolescents with diabetes mellitus," Diabetic Medicine, vol. 16, no. 1, pp. 31-34, 1999.

[26] A. Aycicek and A. Ipek, "Maternal active or passive smoking causes oxidative stress in cord blood," European Journal of Pediatrics, vol. 167, no. 1, pp. 81-85, 2008.

[27] D. L. Cochran-Black, L. D. Cowan, and B. R. Neas, "The relation between newborn hemoglobin $\mathrm{F}$ fractions and risk factors for sudden infant death syndrome," Archives of Pathology and Laboratory Medicine, vol. 125, no. 2, pp. 211-217, 2001.

[28] G. S. Metsios, A. Stavropoulos-Kalinoglou, J. J. C. S. V. van Zanten et al., "Rheumatoid arthritis, cardiovascular disease and physical exercise: a systematic review," Rheumatology, vol. 47, no. 3, pp. 239-248, 2008.

[29] S. R. Myers, J. A. Spinnato, M. T. Pinorini-Godly, C. Cook, B. Boles, and G. C. Rodgers, "Characterization of 4aminobiphenyl-hemoglobin adducts in maternal and fetal blood samples," Journal of Toxicology and Environmental Health A, vol. 47, no. 6, pp. 553-566, 1996.

[30] A. D. Flouris, B. E. Faught, and P. Klentrou, "Cardiovascular disease risk in adolescent smokers: evidence of a 'smoker lifestyle," Journal of Child Health Care, vol. 12, no. 3, pp. 221231, 2008.

[31] J. P. Cooke and P. S. Tsao, "Is NO an endogenous antiatherogenic molecule?" Arteriosclerosis and Thrombosis, vol. 14, no. 5, pp. 653-655, 1994.

[32] G. S. Metsios, A. Stavropoulos-Kalinoglou, A. Sandoo, et al., "Vascular function and inflammation in rheumatoid arthritis: the role of physical activity," The Open Cardiovascular Medicine Journal, vol. 23, no. 4, pp. 89-96, 2010.

[33] S. A. Kharitonov, R. A. Robbins, D. Yates, V. Keatings, and P. J. Barnes, "Acute and chronic effects of cigarette smoking 
on exhaled nitric oxide," American Journal of Respiratory and Critical Care Medicine, vol. 152, no. 2, pp. 609-612, 1995.

[34] A. D. Flouris, C. I. Vardavas, G. S. Metsios, A. M. Tsatsakis, and Y. Koutedakis, "Biological evidence for the acute health effects of secondhand smoke exposure," American Journal of Physiology, vol. 298, no. 1, pp. L3-L12, 2010.

[35] T. Raupach, K. Schäfer, S. Konstantinides, and S. Andreas, "Secondhand smoke as an acute threat for the cardiovascular system: a change in paradigm," European Heart Journal, vol. 27, no. 4, pp. 386-392, 2006.

[36] K. A. Roberts, A. A. Rezai, K. E. Pinkerton, and J. C. Rutledge, "Effect of environmental tobacco smoke on LDL accumulation in the artery wall," Circulation, vol. 94, no. 9, pp. 2248-2253, 1996.

[37] K. L. Vork, R. L. Broadwin, and R. J. Blaisdell, "Developing asthma in childhood from exposure to secondhand tobacco smoke: insights from a meta-regression," Environmental Health Perspectives, vol. 115, no. 10, pp. 1394-1400, 2007.

[38] G. S. Metsios, A. D. Flouris, and Y. Koutedakis, "Passive smoking, asthma and allergy in children," Inflammation and Allergy. Drug Targets, vol. 8, no. 5, pp. 348-352, 2009.

[39] Working Party of the Royal College of Physicians, "Smoking and the Young," London, UK, 1992.

[40] R. Otsuka, H. Watanabe, K. Hirata et al., "Acute effects of passive smoking on the coronary circulation in healthy young adults," Journal of the American Medical Association, vol. 286, no. 4, pp. 436-441, 2001.

[41] J. Barnoya and S. A. Glantz, "Cardiovascular effects of secondhand smoke: nearly as large as smoking," Circulation, vol. 111, no. 20, pp. 2684-2698, 2005.

[42] N. Priest, R. Roseby, E. Waters et al., "Family and carer smoking control programmes for reducing children's exposure to environmental tobacco smoke," Cochrane database of systematic reviews, no. 4, p. CD001746, 2008.

[43] M. Ezzati, S. J. Henley, M. J. Thun, and A. D. Lopez, "Role of smoking in global and regional cardiovascular mortality," Circulation, vol. 112, no. 4, pp. 489-497, 2005. 


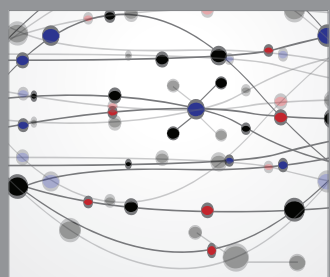

The Scientific World Journal
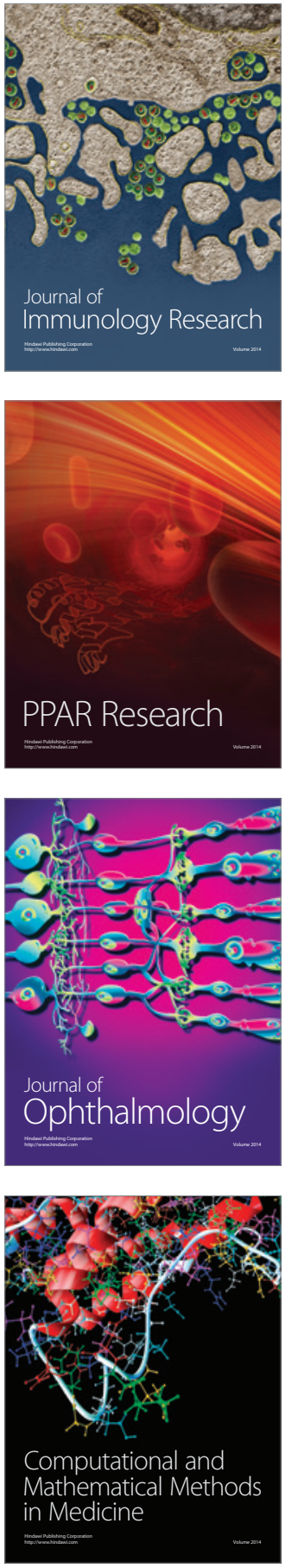

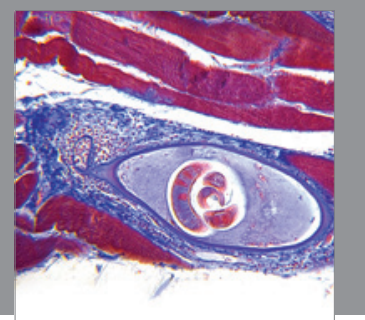

Gastroenterology

Research and Practice
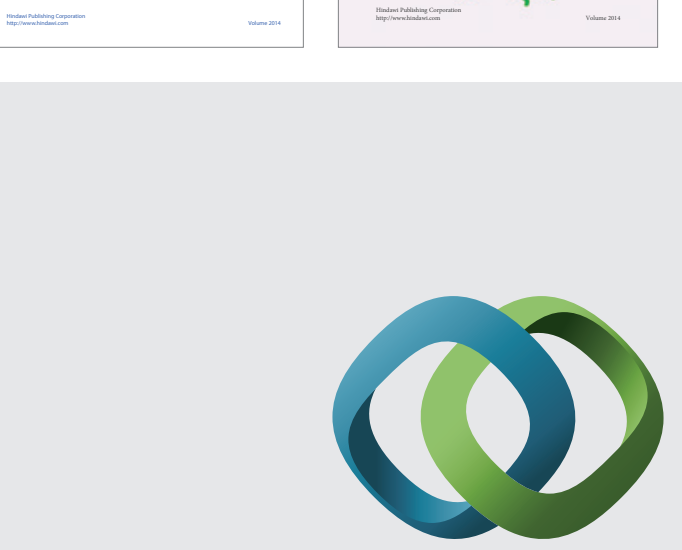

\section{Hindawi}

Submit your manuscripts at

http://www.hindawi.com
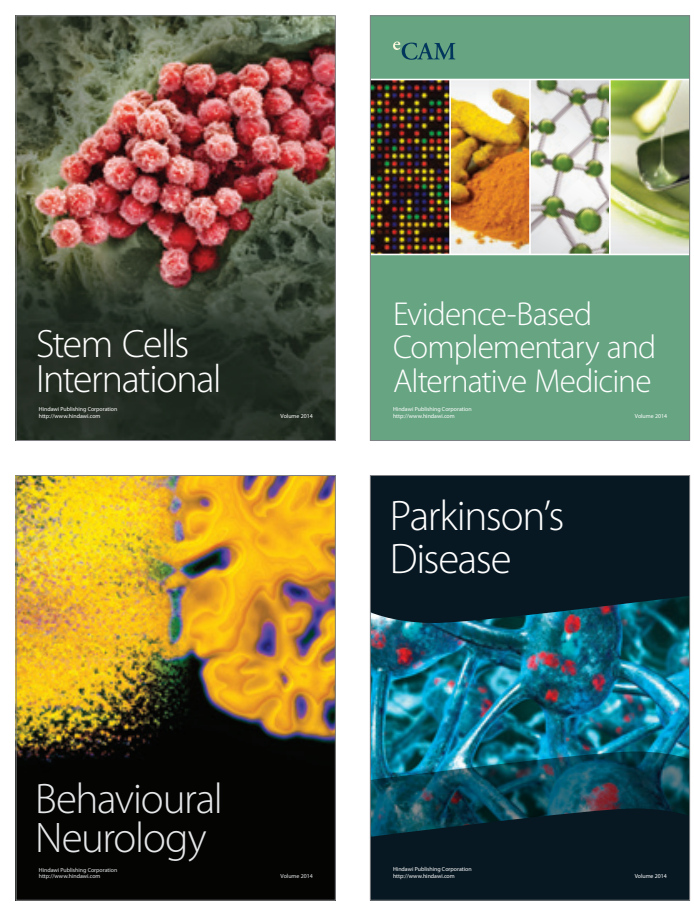

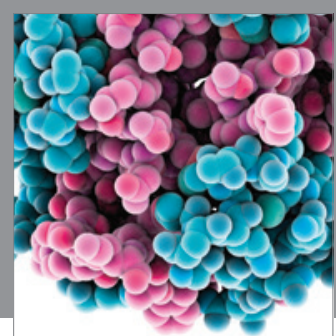

Journal of
Diabetes Research

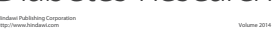

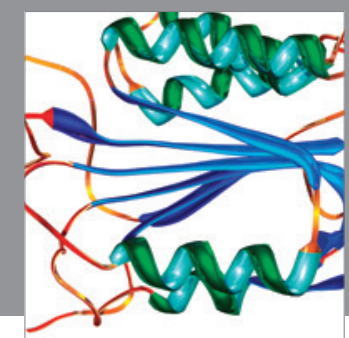

Disease Markers
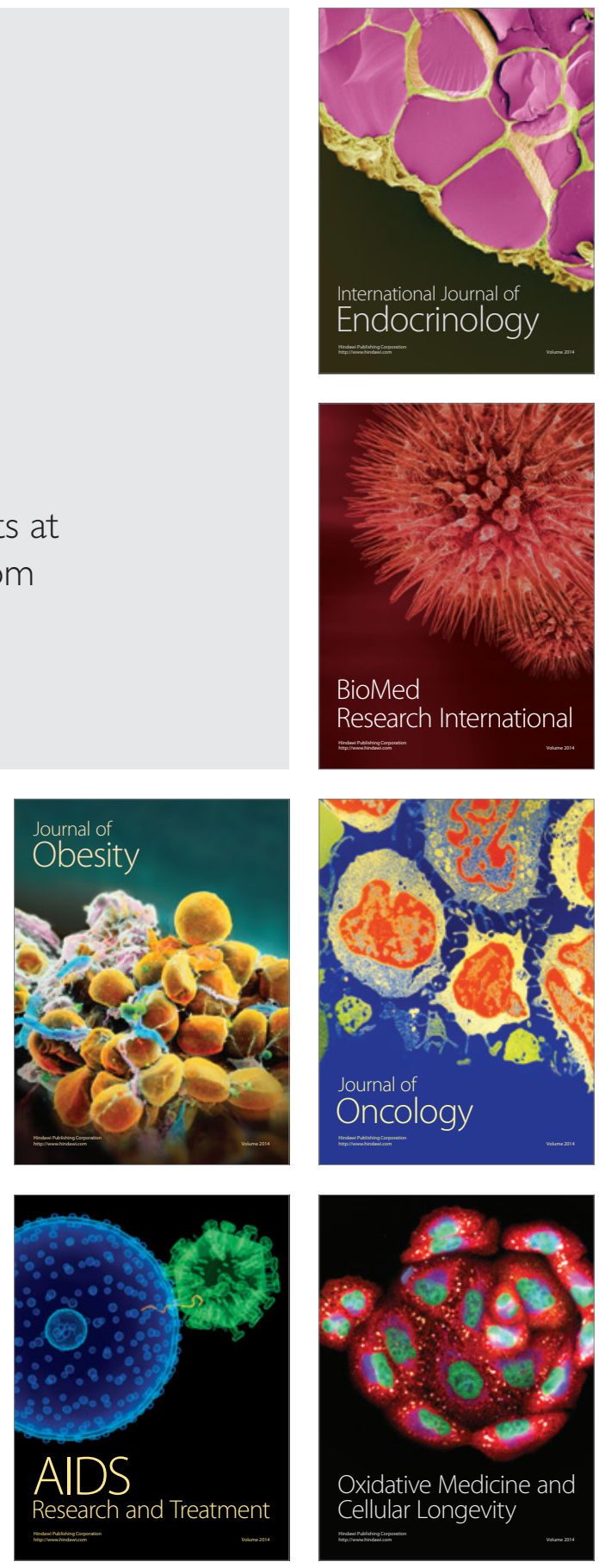